\title{
Una estética deleuzeana: génesis, figura y modulación ${ }^{1}$
}

\section{A Deleuzean Aesthetics: Genesis, Figure and Modulation}

\author{
Felipe Larrea \\ Facultad de Artes, Universidad de Chile \\ Santiago, Chile \\ larrea.felipe@gmail.com
}

\section{Resumen}

Este artículo indaga en la construcción de una estética en la filosofía de Gilles Deleuze más allá del período en su obra donde el arte posee una atención privilegiada. Para Deleuze, la estética no significa simplemente una zona disciplinar de la filosofía: la desarrolla desde sus primeros trabajos hasta Différence et répétition y Logique du sens. Conceptos como el de génesis, signo o fuerzas, entre otros, predominan en su trabajo de los años sesenta y sostienen una relectura del empirismo - "empirismo trascendental"- que enunció como una estética. La impronta metafísica de estos problemas será retomada en sus escritos de los años ochenta en que el arte comparece de manera más directa.

Palabras claves: estética, génesis trascendental, sensación, figura, modulación.

\section{Abstract}

The article explores the construction of an aesthetics in the philosophy of Gilles Deleuze beyond the period of his work where art (music, painting and cinema) obtains direct attention. According to Deleuze, aesthetics is not simply a disciplinary zone of philosophy, but is derived from a series of formulations developed from his earliest works until Différence et répétition and Logique du sens. During the sixties, concepts such as genesis, sign or forces, among others, stand out in his work to serve a rereading of empiricism - "transcendental empiricism"- which he understood as an aesthetics. Deleuze resumes the metaphysical imprint of these problems in the eighties to address artistic issues.

Keyworks: aesthetics, transcendental genesis, sensation, figure, modulation.

1 Este trabajo se inscribe en el marco del Proyecto Fondecyt de Iniciación N 11150732 "El dinamismo singular de la relación: elementos para una reconstrucción de la ontología relacional a partir de una teoría de las multiplicidades (Simondon, Deleuze)", cuyo investigador responsable es el Dr. Cristóbal Durán. El autor del presente artículo es tesista doctoral en dicho proyecto. 


\section{Introducción}

La filosofía de Gilles Deleuze ha tenido como preocupación fundamental el problema de lo estético no solo en sus incursiones en el terreno de la música, de la pintura, el cine y, tempranamente, en la literatura, sino que también en tanto objeto de profunda reflexión filosófica. Sobre todo porque su pensamiento posee una herencia marcadamente kantiana, donde la tematización en torno a la estética tiene relación con pensar las condiciones que fundamentan -en un amplio margen- tanto la experiencia como el juicio. Es este doble vínculo el que nos parece sumamente necesario de explicitar, y de implicar, para darle un estatuto primordial a la hora de abordar su imagen del pensamiento. Ahora bien, como decíamos, tempranamente la literatura se ubicó como una disciplina creativa que a Deleuze le interesó sobre manera para su propio pensamiento. Por lo mismo dedicó libros a dos escritores, Marcel Proust (Proust et les signes) y Leopold Von Sacher-Masoch (Présentation de Sacher-Masoch), para luego, unos años después, publicar en colaboración con Félix Guattari Kafka. Pour une littérature mineure (1975). Sin embargo, no es que la aproximación a la literatura o el arte sea un asunto hacia el cual se dirige Deleuze para interpretar a partir de un pensamiento ya compuesto o formulado; más bien, a partir de Proust y de Sacher-Masoch, extraerá elementos con los que se conectará y hará proliferar una imagen de pensamiento alejado de los tópicos referenciales de cualquier filosofía del arte. Esto constituye una de las aristas más importantes a la hora de definir la estética que Deleuze diseña: una que no consiste en una zona de pensamiento desde la cual irá a "interpretar" al arte como una esfera separada de la filosofía, por el contrario, le dará una autonomía que al mismo tiempo esgrimirá en proximidad, en el sentido de que la filosofía también es una disciplina estrictamente creativa (Deleuze y Guattari, Qu'est-ce que la philosophie? 11-2). Es necesario remarcar que, luego del trabajo con Guattari en los años sesenta, Deleuze comienza a tener como objetivo otras artes, como lo exponen, por ejemplo, los pasajes dedicados a la música en Mille Plateaux en 1980 (381-483), el libro sobre el pintor Francis Bacon publicado un año después, y, posteriormente, sus dos obras dedicadas a la imagen cinematográfica, Cinéma 1. L’image-mouvement (1983) y Cinéma 2. L'image-temps (1985). Independientemente de estos antecedentes que parecieran sugerir que para Deleuze el arte aparece en un período determinado de trabajo, creemos que -y lo planteamos como objetivo de este artículo- no podría ser reconocido como una preocupación ulterior, sino que dicha dimensión se encuentra modulada en el desarrollo filosófico que elabora en sus primeras obras.

La propuesta de investigación que acá esbozamos está reafirmada por una serie de comentadores contemporáneos de la obra de Deleuze, quienes han insistido en el pliegue que su obra realiza entre una cierta metafísica y una determinada estética. Por ejemplo, Véronique Bergen ha señalado que esta nueva imagen del pensamiento que el "empirismo trascendental" propicia desde los primeros escritos de nuestro 
autor "está explícitamente emparentada a la esfera artística" (78). Sin embargo, ha sido cierta discusión esbozada por Arnaud Villani la que a nosotros nos parece más pertinente de referir a modo de introducción, ya que él es quien ha mostrado cierta sospecha sobre el querer circunscribir al pensamiento deleuzeano en una estética. En un texto titulado "De l'esthétique à l'esthésique: Deleuze et la question de l'art" señalará una distancia bastante frontal con dos lecturas que han buscado construir -bajo modos disímiles- una estética propiamente deleuzeana. Por un lado, con el libro de Mireille Buydens (Sahara. L'esthetique de Gilles Deleuze), que es una de las primeras recepciones del pensamiento de Deleuze, en el año 1990; y por otro, con las variadas intervenciones sobre el pensamiento estético de Deleuze realizadas por Jacques Rancière; pero, por sobre todo, Villani se detiene en el texto "Existe-t-il une esthétique deleuzienne?". Según su lectura, el libro de Buydens no acierta en leer un concepto clave en la obra de Deleuze, a saber, el de multiplicidad, pues lo enuncia en una contraposición bastante marcada con respecto a la noción de forma. Si bien la estética de Deleuze, dirá Villani, se piensa a contrapelo de la forma, esta no podría ser sencillamente un objetivo o una insistencia negativa de su filosofía; ni mucho menos podría oponerse a ella la multiplicidad, puesto que así se le daría un estatuto meramente secundario, derivativo (104-7). Con respecto al trabajo de Rancière, Villani establece de manera más fehaciente sus distancias: no logra concebir que las nociones que Deleuze despliega a propósito del arte tengan cabida dentro de una tradición del pensamiento estético -tal como lo define Rancière- no solo en su comentario a Deleuze, sino que también en su propio pensamiento. Esto quiere decir que la estética, para Deleuze, no tiene el mismo significado que el arco de referencias que el mismo Rancière diseñó para pensar el régimen estético de las artes, uno que va, por ejemplo, de Hegel a Novalis, pasando por Flaubert. Existe cierta omisión con respecto a que el "empirismo trascendental" desplaza una concepción de lo sensible que no tiene mucha relación con el sensible heterogéneo tematizado por Rancière, en el sentido de que para Deleuze lo sensible es, antes que todo, asimétrico y diferencial, y no se posa sobre un sensible empírico, más bien debe pensarse en un sentido estrictamente trascendental (117). En definitiva, para Villani, ambas lecturas son imprecisas. Para él no existe un trabajo más profundo sobre los significados de ciertas nociones claves en Deleuze, como es el caso de la multiplicidad en Buydens, incluso más fuertemente en cómo Rancière pareciera rápidamente subsumirlo en una estética de corte tradicional sin tener en la mira el trabajo que desplegó, por ejemplo, en Différence et répétition, trabajo que daría cuenta de una lectura del problema estético más allá del arte como campo autónomo. Para nuestros intereses, el texto de Villani es fundamental en cuanto articula una discusión en curso sobre Deleuze. Sin embargo, nos parece que el concepto de lo estésico es insuficiente con respecto a lo que el mismo Deleuze elabora en Différence et répétition como "empirismo trascendental" que, como pasaremos a revisar, es descrito directamente en tanto una estética, sin ninguna declinación o alteración del término. Dentro de esta discusión que abre Villani, nos interesa insistir 
en la necesidad de enunciar cierta idea moderna que ha estado velada por aquello que el mismo Rancière ha llamado "el malestar de la estética"; es decir, por la idea de que la estética ha tomado el lugar de la metafísica que, como describió Aristóteles, consistía en la filosofía primera, ciencia del ser, superior a cualquier saber regional (Metafísica 269-70). Ahora bien, la estética en un sentido poskantiano tomaría este lugar, es decir, el lugar desde donde se articula una filosofía o un pensamiento.

Para fundamentar esta última cuestión nos proponemos recorrer o aproximarnos a esta estética deleuzeana. En primer lugar, abordaremos de qué manera la lectura que establece Deleuze del empirismo lo lleva en Différence et répétition a formularlo como una estética, según la cual cierta noción de la sensibilidad en un sentido trascendental es fundamental para comprender este desplazamiento. En segundo lugar, nos aproximaremos a cierta deriva que se encuentra en Logique $d u$ sens, pero que un año antes estaba en Différence et répétition más o menos instalada. Con esto nos referimos puntualmente a que la estética para Deleuze tiene que ver con una torsión de lo trascendental en sentido kantiano, y para ello pareciera que el autor francés provoca un ensamble, un choque, que pliega a las dos estéticas kantianas: la estética entendida según La crítica de la razón pura, y la estética trabajada dentro del marco de la tercera crítica, La crítica del juicio. En tercer lugar, nos instalaremos en lo que más comúnmente se ha llamado estética deleuzeana, abierta en 1981 con sus investigaciones sobre pintura. Allí pondremos la atención en deslindar su concepto de figura en oposición a la figuración, donde la noción de cliché nos parece elemental porque tiende un puente con sus estudios posteriores, es decir, sus trabajos sobre cine. Por último, nos detendremos en el concepto propuesto por Gilbert Simondon de modulación, trabajado por Deleuze para pensar la diferencia de naturaleza entre la pintura y la fotografía, distinción que también encontraremos en Cinéma 1. L'imagemouvement, libro donde el concepto de modulación le permite a Deleuze sostener la infinita variación de la materia moviente, cuestión elemental para sostener su lectura sobre la imagen-cinematográfica.

\section{Del empirismo trascendental como estética}

La mención a la obra de arte aparece para Deleuze en variadas ocasiones, como si fuera en ella donde la imagen de su pensamiento se consumara. Así lo expresa un pasaje de Différence et répétition, específicamente al final del primer capítulo, donde se propone deslindar y dar consistencia a la noción de diferencia que ese trabajo, en términos amplios, impulsa. Ahí señala una relación importante entre la obra de arte y el concepto de diferencia, ya que la diferencia puede ser definida como una "unidad última" que debe ser comprendida no en un sentido vacío o, por el contrario, como fundamento, sino que en el sentido de estar perpetuamente remitiendo "a otras diferencias que no la identifican sino que la diferencian" (79). Es, de este modo, que 
la diferencia no consiste en la subordinación a una identidad o representación, más bien es producida difiriendo a cada cosa, a cada ser, y en la obra de arte moderna, afirma Deleuze, es donde estas señas y condiciones se dan de manera más visible. Es que la obra abandona el terreno de la representación para volverse "experiencia", formulación bastante cercana a la advertida un año después en Logique du sens -en la cual nos detendremos con mayor precisión en el próximo acápite- cuando advierte la apertura de una obra de arte que se piense como "experimentación" (300). Ahora bien, dentro de este pasaje de Différence et répétition, dicha noción de experiencia -que sin duda debemos tener en mira- es homologada con lo que Deleuze llamará "empirismo trascendental", aunque extienda su dominio al referirlo también como "ciencia de lo sensible" (79). Sin embargo, es aquí donde el problema de lo sensible parece ser clave en esta configuración, ya que la estética no podría ser definida desde un sensible en tanto posibilidad, como si lo sensible fuera un terreno donde "se puede" representar algo. Tampoco se debe entender la estética como lo opuesto, es decir, en tanto una sustracción de la representación que solo dejaría "una rapsodia de sensaciones" (79). La operación de esta estética se vincula a una concepción de la sensibilidad bajo otro ejercicio que se condice con la imagen del pensamiento que Deleuze insta a forjar, es decir, con su irrupción a partir de fuerzas que se constituyen en y desde lo sensible. Esta apreciación está fundamentada en el libro que seguimos, pues el empirismo propiamente deleuzeano se formula con el examen de un (in)sensible que fuerza a pensar, una violencia que se ejerce desde lo no-sentido o el sentiendum y produce que la sensibilidad vaya más allá de sí:

En verdad el empirismo deviene trascendental, y la estética, una disciplina apodíctica, cuando nosotros aprehendemos directamente en lo sensible lo que no puede ser sino sentido, el ser mismo de lo sensible: la diferencia, la diferencia de potencial, la diferencia de intensidad como razón de lo diverso cualitativo (79-80).

Para comprender en qué sentido el empirismo deviene trascendental, formando un pliegue con este, habría que explicarlo, en principio, a partir de lo que Deleuze llama la discordancia de las facultades y, en específico, de la sensibilidad. Una de las características fundamentales del "empirismo trascendental" es el ejercicio al que es llevada la sensibilidad, pues en su ejercicio trascendental tendrá como objeto lo que solo puede ser sentido por, como decíamos, el sentiendum, también llamado por Deleuze el "ser de lo sensible" (216). De este modo, el ejercicio trascendental de la sensibilidad es provocado a partir de un encuentro que germina a la sensibilidad en el sentido, y que, posteriormente, desquicia el orden de las facultades. Es en Proust donde Deleuze vio que el signo es el objeto de este encuentro (Proust et les signes 24-5), convirtiéndose de esta manera -como advertirá Anne Sauvagnargues- en una fuerza o en un modo de la afección (Deleuze et lart 54). De allí que el signo para Deleuze sea una noción fundamental. En su trabajo sobre Nietzsche ya había advertido la presencia de una suerte de "sintomatología" indispensable para el ejercicio del 
pensamiento, que luego profundiza en sus estudios vinculados a la literatura, como es el caso de Proust y Sacher-Masoch. Ahora bien, es a partir de esto que el signo no se relaciona con el buen pensar, de hecho se le opone radicalmente: el encuentro constituye una violencia que no solo hará germinar lo sensible sino que también al mismo pensamiento. Estos análisis, un par de años después en Différence et répétition, se volverán más precisos cuando Deleuze hable del "ser de lo sensible" en tanto forma en que la facultad de lo sensible no se reconocerá a sí misma en su ejercicio, pues no podrá reconocerse en aquello ante lo cual es afectado. Con respecto al pensamiento, ocurre el mismo proceso, es decir, existe algo - un signo- que fuerza al pensamiento a germinar, produciéndose una génesis del pensar, pues, al igual que Heidegger, ${ }^{2}$ Deleuze señalará que todavía no pensamos, pues el pensamiento no se encuentra, bajo ningún motivo, dado. Del mismo modo, el encuentro, su signo, es lo insensible que germinará lo sensible o el ser mismo de lo sensible (Différence et répétition 182). Sin embargo, ¿en qué consistiría esta propiedad tan singular de ser lo insensible? Podríamos señalarlo bajo dos modulaciones. Por un lado, como habíamos expuesto, no puede ser reconocido, no está del lado del reconocimiento, sino que debe ser vislumbrado desde la óptica deleuzeana del "encuentro", desde aquello que choca o fuerza. Es en ese sentido que no puede ser reconocido desde un ejercicio empírico de la sensibilidad. Por otro lado, al no ser parte de un ejercicio propiamente empírico es propuesto como lo trascendental y, por lo tanto, se le advierte como una forma insensible. En otros términos, debemos señalar lo dicho en un primer momento con respecto a la diferencia, en el hecho de que el sentiendum no podría, bajo ningún carácter, ser relacionado con ninguna mediación representativa ni figurativa "sino, por el contrario, de estados libres o salvajes de la diferencia en sí que son capaces de llevar las facultades a sus límites respectivos" (187). La diferencia en sí es aquello que crea este ejercicio discordante y trascendental de la sensibilidad. Por este motivo es que funciona como lo insensible para la experiencia en un nivel ordinario, es decir, en un sentido meramente empírico.

De ese modo, para Deleuze, la sensibilidad debe ser definida a partir de una génesis que ocurre ahí donde el sentido común ya no funciona, donde se disloca cualquier acuerdo presupuesto de las facultades. Es la acción del signo, de una lógica del encuentro, de cierta pasión que se opone a la necesaria y estabilizadora imagen del reconocimiento. ${ }^{3}$ Pues si la potencia de un algo que fuerza a pensar -o crear, dirá

2 En su estudio sobre Nietzsche, Deleuze señalará que en él habría un origen de la clásica sentencia heideggeriana expuesta en Qué significa pensar: "Lo que más da que pensar de suyo, lo más merecedor de pensarse... es el hecho de que nosotros todavía no pensamos" (Heidegger 18).

3 "Muchos están interesados en decir que todo el mundo sabe «esto", que todo el mundo reconoce esto, que nadie puede negar esto. (Triunfan fácilmente, siempre que un interlocutor fastidioso no se levante para responder que no quiere estar así representado, que niegue y que no reconozca a los que hablan en su nombre.) El filósofo, es verdad, procede con más desinterés: lo que él plantea como universalmente reconocido es tan solo lo que significa pensar, ser y yo [moi], es decir, no un esto, sino la forma de la representación o del reconocimiento en general. Esa forma sin embargo tiene una materia, pero una materia pura, un elemento. Ese elemento solo consiste en el planteamiento 
Deleuze- no podría ser figurado sino a partir de un encuentro, su "contingencia", su "azar", fuerza al pensamiento como a la sensibilidad a no reconocerse. Es en este sentido que es lo insensible, pues lo sensible, en sentido figurado -figurativamente hablando-, está del lado del reconocimiento: de aquello que podemos reconocer a partir de los sentidos. Por esta razón, el encuentro es lo insensible, aquello que no puede ser sino sentido, pero que de todas formas, si se manifiesta, toma la forma de lo insensible, ya que lo sentido está en una capa de figuración, de reconocimiento o de cierta reminiscencia. El ser de lo sensible constituye el elemento fundamental por el cual emerge o germina lo sentido, es decir, la sensibilidad misma: "el objeto del encuentro, por el contrario, realmente hace nacer la sensibilidad en el sentido" (Différence et répétition 182). François Zourabichvili vinculará lo que hemos estado recogiendo con un problema que se encuentra en el primer trabajo de Deleuze, Empirisme et subjetivité. Allí Deleuze señala la potencia de pensar en una exterioridad de las relaciones (66), establecer un afuera absoluto. Esta exterioridad no es otra cosa que el terreno del encuentro, del encuentro que fuerza a pensar a partir de una relación que no depende bajo ningún término de sí misma (Zourabichvili, Deleuze. Filosofía del acontecimiento 34).

Un empirismo superior, entonces, sería aquel que afirma dicha contingencia que veníamos apuntando: este azar de los encuentros que deben crear una imagen del pensamiento opuesta a una imagen dogmática, anclada en el buen pensar y en el reconocimiento. Es de este modo que cuando Deleuze aborda directamente el problema del arte, la imagen con la cual se aproximará no difiere de estos análisis que hemos revisado hasta acá, ya que lo comprendido por arte debe estimarse desde una forma en que lo sensible sea algo que debe captarse o aprehenderse. Es decir, aquello que el arte realiza no es sino el asistir a una génesis de lo sensible. La estética deleuzeana, así, comprendería fundamentalmente un potencial genético, pues la figura de la aprehensión o la captura, en Francis Bacon. Logique de la sensation, aparecerá bajo la seña de las fuerzas: la pintura, su especificidad, radica en producir o dar muestra de fuerzas invisibles, es decir, en capturar algunas fuerzas que no son visibles (sentidas) por las facultades o las formas de la sensibilidad. Es preciso señalar que Deleuze define, en este texto, al arte no como un reproductor o un inventor de formas, sino como advertíamos, bajo el procedimiento de la captura o la aprehensión (57), justamente, de fuerzas que deben hacerse visibles. Ahora bien, el concepto de fuerza que Deleuze insta a pensar había sido definido de forma temprana como condiciones bajo las cuales aparecerá tanto el pensamiento como lo sensible. Es por esta razón que debemos aproximarnos a lo que Deleuze comprende por "condiciones".

del pensamiento como ejercicio natural de una facultad, en el presupuesto de un pensamiento natural dotado para lo verdadero, en afinidad con lo verdadero, bajo el doble aspecto de una buena voluntad del pensador y de una recta naturaleza del pensamiento" (Différence et répétition 202-3). 


\section{El problema de las condiciones}

En Presentación de Gilles Deleuze, José Luis Pardo señala que existe solo una "imagen posible" que nos podemos hacer de lo que Deleuze - de la mano de Bergson ${ }^{4}$ llamará "condiciones de la experiencia real". Dicha imagen no es otra que el "arte", o más bien -con mayor precisión -la "obra de arte", donde "se produce ese trabajo sobre la fantasía que deja de presentarla como una realidad imperfecta o mutilada con respecto a lo que se supone que "representa" y hace de ella algo virtual pero no abstracto, real y autónomo frente a la empiricidad endurecida de lo actual” (114-5). Comprender que las condiciones son reales es, de cierta manera, rebasar el mero condicionamiento al que Kant había reducido a la sensibilidad, por ejemplo. Pues si la sensibilidad es una condición real esto significa que no está dada, no es una forma a priori de todo aparecer, así como de todo conocimiento; más bien constituye una suerte de producción, de germen o, en otras palabras, es la muestra de una génesis de lo sensible en la discordia o disyunción de las facultades. Esta génesis no es otra cosa que el ser mismo de lo sensible, una forma no figurativa de lo sensible. De allí que se nos presenta como lo insensible, imperceptible para el acuerdo de las facultades.

Ahora bien, el problema del condicionamiento trascendental versus lo que Deleuze comprende por una génesis trascendental, debe estimarse bajo la siguiente consideración si se quiere comprender qué podría significar una estética deleuzeana. En Logique du sens, sentencia una afirmación enigmática, si se la mira de forma parcial a partir del lugar en que se encuentra, pero también, si no es leída al menos desde lo que hasta acá hemos querido plantear. El siguiente fragmento encara cierto significado preciso de lo que se piensa por estética y su vínculo con la experiencia. Lo citamos a continuación en aras de aproximarnos a una definición de una lógica de la sensación en pintura que, para nosotros, coronaría un trabajo que el autor francés venía planteando desde sus primeros años:

La estética sufre una dualidad desgarradora (déchirante). Designa, de un lado, la teoría de la sensibilidad como forma de la experiencia posible; del otro, la teoría del arte como reflexión de la experiencia real. Para que los dos sentidos se reúnan, es preciso que las condiciones de la experiencia en general devengan ellas mismas condiciones de la experiencia real; la obra de arte, por su parte, aparece entonces realmente como experimentación (300, cursivas nuestras).

Antes de entrar en el detalle de este pasaje, deberíamos plantear un excurso, puesto que el problema de las condiciones -como de la génesis trascendental- es transversal

4 El desplazamiento desde un pensar sobre las "condiciones de posibilidad de la experiencia" hacia unas "condiciones reales", proviene principalmente de la lectura que Deleuze realiza sobre el método de la intuición bergsoniano, en el sentido de que este método se propone establecer las condiciones reales para el planteamiento de un problema, ahí donde los problemas se crean, y no están sólo al servicio del conocimiento posible (Le bergsonisme 13). 
al trabajo que Deleuze sostiene tanto en Différence et répétition como en Logique du sens, independientemente de lo que podríamos diferenciar -cuestión que se ha hecho entre algunos comentadores- como tratamientos disímiles en ambos libros sobre la cuestión que nos convoca en este acápite. Pues mayormente se ha tendido a leer el problema de lo trascendental a partir de los encuadres del primero de aquellos libros, tal como lo realiza Anne Sauvagnargues en su libro dedicado íntegramente a despejar qué se entiende por "empirismo trascendental". Por otro lado, François Zourabichvili lo ha trabajado desde este lugar tanto en el vocabulario que le dedica a Deleuze, como en Deleuze, una filosofía del acontecimiento. A su vez también es remarcado por el vocabulario que editan Sasso y Villani a partir de la idea del “empirismo superior” (127). En un importante trabajo, Gonzalo Montenegro señalará esta inflexión, es decir, que de manera más preponderante se ha tendido a leer el asunto de lo trascendental desde las directrices de Différence et répétition, pues ahí "lo que prima es la formulación de una doctrina de las facultades, mientras que en $L S$ dicha formulación está casi ausente y la misma propuesta se sostiene en términos de la descripción de los principios que rigen en un campo trascendental" (Empirismo trascendental 95).

En Différence et répétition la lectura de lo trascendental estaría principalmente abocada a trabajar mucho más el texto kantiano, específicamente en, como habíamos sostenido, torcer la doctrina de las facultades; en cambio, en Logique $d u$ sens, todo pasa más bien por cotejar cierta lectura del ego trascendental sartreano, en la medida que abre y discute con la fenomenología en términos amplios, a la vez que se explora una "definición de un ámbito pre-individual en que las relaciones de determinación mutua entre singularidades permiten estatuir los principios de individuación conforme las singularidades se organizan para dar lugar al individuo" (95) o, en otras palabras, una lectura mucho más dirigida al pensamiento de Simondon.

Señalamos esto porque habría que tenerlo en cuenta a la hora de abordar el pasaje de Logique du sens que atendimos recién. Nosotros adscribiríamos a una suerte de pliegue o también, por qué no, a una suerte de amarre del problema de la estética con respecto a lo trascendental, que no solo proviene de Différence et répétition sino que más atrás, de los textos sobre Bergson, Nietzsche, Hume. Pues aquello que es llamado en el primer apéndice de Logique du sens como "teoría de la sensibilidad" no es otra cosa que una destinación estética que aún conviene a la sensibilidad como condición para el conocimiento y, a su vez, la sensibilidad constituye una facultad que erigiría una forma posible a ser representada. En otras palabras, una sensibilidad que aún confía en la posibilidad de una teoría del conocimiento, a partir de las condiciones de posibilidad de la experiencia. Por otro lado, la teoría del arte simplemente se esgrime desde la distancia de la reflexión, es decir, se relaciona con la experiencia real dogmáticamente, transformándose en un material para la representación. De modo hipotético, se podría enunciar que lo señalado por Deleuze ahí son los dos modos de la estética para Kant: primero, la estética trascendental de la primera crítica (Crítica de la razón pura 65-92); y segundo, la estética comprendida desde la tercera crítica (Crí- 
tica del juicio 125-73). Ahora bien, Deleuze pretende hacer chocar ambas posiciones, para que de ellas devenga una estética que piensa a la obra de arte como verdadera experimentación. Es en este sentido que aquello que podríamos llamar "experiencia estética" tiene un doble vínculo: por un lado, hacia la obra de arte, y por el otro, hacia cierta "sensibilidad natural", insensible, de la misma naturaleza.

A propósito de esto último es que José Luis Pardo dirá que lo percibido sensiblemente, según Deleuze, jamás será lo dado, más bien será una producción sin sujeto, sin agente que no produzca en la naturaleza ni en lo sensible (Las formas de la exterioridad 262-63). La obra de arte no emanaría de ninguna conciencia creadora, sino que de una amalgama creativa previa a la conciencia, la cual configura de cierta forma cualquier tipo de condición de existencia, tanto de la subjetividad como de la experiencia. Las condiciones, de esta manera, no son únicamente lo que configura la percepción de lo dado y la posibilidad del conocer, sino que, en tanto condiciones reales, son las que producen creativamente lo dado y lo pensado, estableciendo unas constituciones donde sus determinaciones son recíprocas. Por ello, es que Deleuze realmente tuerce a Kant, en el sentido de que las condiciones de la experiencia se vuelven parte de un entramado que involucra al funcionamiento de las cosas, tanto de la materia como del mismo proceder del pensamiento. Podríamos advertir que ahí donde decimos "experiencia real" encontraríamos la potencia de la obra de arte como sensación, o como experimentación, que no es otra cosa "que una liquidación de las coordenadas sujeto/objeto en una visión o una audición que alcanza el ser mismo de lo sensible" (Lapoujade 105). Esto lo decimos porque la sensación no es sino otro nombre para describir aquello insensible que germina cuando la sensibilidad es llevada a un límite. Junto con el concepto de fuerza que Deleuze retoma en Logique de la sensation, ambas pueden ser comprendidas, a su vez, como las condiciones reales y germinativas de la sensación. Por lo mismo, son enunciadas por Deleuze como fuerzas invisibles, es decir, tanto insensibles como imperceptibles.

\section{La lucha contra los clichés: la figura}

Para retomar aquello que habíamos advertido en la introducción, sobre el concepto de sensación -es decir, sobre aquello que Deleuze elaborará como pivote esencial de su estética-, deberíamos adentrarnos mínimamente en el concepto de figura, que aparecerá definido en Logique du sens en tanto forma sensible de la sensación (39). ¿De qué se tratará efectivamente esta forma sensible? Si la sensación es una violencia, esta no deberá ser pensada a partir de una violencia figurativa o, como lo expresa Deleuze, no consiste en lo sensacional. El trabajo sobre Francis Bacon se posa efectivamente sobre este punto, es decir, en dar muestras de que sí existe en la obra del pintor irlandés una suerte de violencia, una que es propiamente de la sensación. Si, como habíamos señalado, lo sensible para Deleuze no tiene ninguna relación con lo 
sensible en sentido figurado, ni mucho menos con las formas de la sensibilidad, más bien lo tiene con la germinación de lo no-sentido o lo insensible. A este haber podríamos señalar que, si es definible la sensación, lo es precisamente por esta característica: encontrarse en una capa no figurativa, donde no logra ser localizada bajo ninguna forma empírica. Sin embargo, Deleuze plantea que es la figura aquello que emerge como una "forma sensible" de la sensación. Aunque sea paradojal en principio, se debe precisar que la figura no remitiría a una figuración primaria: "Bacon no ha dejado de querer eliminar lo 'sensacional', es decir, la figuración primaria de lo que provoca una sensación violenta. Tal es el sentido de la fórmula: 'he querido pintar el grito antes que el horror"' (42). Todo esto es coherente con lo que unas páginas más adelante Deleuze emplazará, aquella remisión a que la sensación tiene una condición real, que es la de las fuerzas (57). Anne Sauvagnargues puntualizará mucho más esta deriva, al observar que la sensación no es otra cosa que una "relación de fuerzas que produce una imagen" (Deleuze et l'art 210). Sin embargo, aquellas fuerzas no son sentidas, la sensación nos donaría "algo" que no está dado, pues no es sentido, ni visible. De ahí que la definición que le dará Deleuze a la pintura sea precisamente la de capturar fuerzas invisibles, para hacerlas visibles o sentidas. Dicho visible proveniente de algo invisible (las fuerzas) es la figura.

La noción de figura es, sin duda, un componente esencial en la configuración de la estética deleuzeana, en la medida en que a partir de ella se elaborará cierta especificidad de la imagen pictórica, pero con la cual creemos que posee una cercanía manifiesta con el momento más acontecimental e irruptivo de lo que Deleuze comprende por imagen cinematográfica. Es que existiría cierto paralelo por abrir entre una evolución de las artes plásticas (pictóricas específicamente) y las artes cinematográficas. Uno de los comentadores de Deleuze que ha puntualizado este problema es Pierre Montebello, quien realiza una observación en torno al capítulo once de L'image-mouvement, donde señala que la lógica de las formas en el cine pertenece al horizonte de la "imagen-acción", es decir, un tipo de imagen subordinada a la forma orgánica (Deleuze, philosophie et cinema 196-242). Esta forma, en pintura, habría comenzado a perfilarse en el arte clásico, específicamente en el arte griego, que Deleuze señalaría como el momento en que el plano se escinde de las formas, articulando una representación orgánica del hombre. El proceder del cine de la imagen-acción no difiere de las coordenadas táctilópticas que Deleuze definirá para el espacio pictórico (Logique du sens 117-22). Esta lógica es contrapuesta a lo que Deleuze alude como la transformación o deformación de las formas o, en otras palabras, la figura. Montebello, de esta manera, arroja cierta luz sobre esta relación, es decir, entre la noción de figura que aparece en el primer estudio sobre cine y lo que se encuentra en el libro sobre Bacon, puesto que en ambos casos "designa el proceso de conjuración o de transformación de la forma orgánica" (69). En el libro sobre Bacon, la figura es aquello que se antepone radicalmente a lo figurativo, al menos es aquello que lo conjura. En tanto que en L'image-mouvement, la figura se antepondrá a las formas orgánicas que contienen a la imagen-acción, aunque 
en su crisis, en la disolución de esta imagen, lo que aparecerá es la imagen ópticasonora pura, tematizada profundamente en los primeros capítulos de L'image-temps.

Es a este haber que pretendemos esclarecer esta relación directa entre una lógica de la sensación y la semiótica de las imágenes que pertenecen a cierto universo cinematográfico. Puesto que la emancipación de los rasgos sensorio-motrices permite comprender una imagen insubordinada a esas directrices alcanzando una pureza óptica y sonora. Esto consistiría en una imagen emancipada del cliché, puesto que Deleuze argüirá que siempre una imagen sensorio-motriz es una imagen-cliché (Cine 1508). Ahora bien, lo del cliché constituye un tópico a considerar dentro de la obra deleuzeana, particularmente, en las dos obras llamadas "estéticas", a saber, el libro sobre Bacon y los dos volúmenes sobre cine. Ya que tanto en los cursos sobre pintura, como en Logique $d u$ sens, Deleuze sostendrá que el tiempo del antes de la obra pictórica-como lucha contra los clichés - es fundamental para aquello que germinará posteriormente con el "hecho pictórico". Todo un trabajo de preparación, de producción, de génesis de la obra pictórica es tematizado por Deleuze. De ahí que aquella imagen de la tela en blanco nunca haya tenido existencia (Logique du sens 83), puesto que, antes de comenzar a pintar, existiría un poblamiento de imágenes, de fantasmas tanto en la tela como en la propia cabeza del pintor. Deleuze nomina como clichés todo aquel poblamiento:

¿Cómo llamar a esas cosas de las que el pintor debe desembarazarse? ¿Qué es esta lucha con fantasmas antes de pintar? ¿Qué son esos fantasmas? Los pintores le han dado a menudo un nombre, casi técnico, en su propio vocabulario: los clichés. Se diría que los clichés están ya sobre la tela antes de que se haya comenzado. Que lo peor está ya ahí. Que todas las abominaciones de lo que es malo en la pintura están ya ahí. Cézanne conocía los clichés, la lucha contra los clichés aún antes de pintar. Como si los clichés estuvieran ahí como bestias que se precipitan sobre la tela, aún antes que el pintor haya tomado su pincel (Pintura. El concepto de Diagrama 42).

En pintura, la lucha contra el cliché es indisociable del ejercicio pictórico. Se debe hacer una catástrofe con los clichés, que es básicamente la operación que realiza el diagrama, luego de ello existe germinación. El diagrama consiste en barrer o hacer catástrofe con todos los datos figurativos anidados en torno a la tela y en la misma subjetividad del pintor. Es, en este sentido, que la catástrofe-germen, producida por el diagrama, resulta necesaria para alcanzar una imagen más profunda que no se encuentre dentro de una esfera representativa ni figurativa. La figura, en Bacon, conjura lo figurativo, pues funciona aislada, no cuenta ninguna historia ni narración, no ilustra. Lo figural, ${ }^{5}$ como habíamos señalado, no remite a una lógica de las formas,

5 Deleuze, al comienzo de Logique de la sensation, alude a un texto al cual le debe el uso del término figura, y de lo figural. Dicho texto corresponde a la tesis doctoral de Jean- François Lyotard, Discours, figure. Ahí Lyotard definirá lo figural en oposición a lo figurativo y, por sobre todo, en su relación con la pintura. Por lo mismo son conclusiones 
en donde sea posible una secuencia entre ellas que refiera a un fondo determinado. Habría que relacionar de manera rigurosa una lógica del fondo pictórico, donde se deposita la acción figurativa de la pintura y lo que en cine sería cierto realismo cinematográfico que encarna la imagen acción (L'image-mouvement 196-97). El nexo sensorio-motor, en los estudios sobre cine, es aquello que debe deformarse para que así irrumpa una imagen pura, que se encuentre emancipada de aquellas directrices figurativas. Ese desplazamiento nos otorga una percepción pura, y no -como diría Bergson- una mera percepción natural, más bien es una operación cercana a la que realiza la figura al conjurar a la figuración.

La relevancia de una noción como la de cliché pasa justamente por ser aquello que se antepone a una estética propiamente deleuzeana. Para una correcta consideración, nos remitimos a una de las características que Deleuze señala que pertenecen a la crisis de la imagen-acción: una cierta toma de conciencia de la existencia de los clichés. ${ }^{6}$ Eso es lo que ocurre en la imagen cinematográfica plenamente moderna, aquella que Deleuze ubica luego de la Segunda Guerra Mundial, específicamente con el neorrealismo en Italia, donde prima el vagabundeo, el quiebre de los enlaces sensorio-motores y la instalación de personajes que parecieran no actuar, sino más bien ser presa de una congoja que los muestra vacilantes y sin capacidad de acción. A todo esto se le suma la batalla frontal del neorrealismo italiano y, posteriormente, la nouvelle vague, contra los clichés. En L’image-mouvement son definidos de la siguiente manera:

...imágenes flotantes, clichés anónimos que circulan por el mundo exterior, pero que también penetran en cada uno y constituyen su mundo interior, hasta tal punto que cada cual no posee en sí más que clichés psíquicos por medio de los cuales piensa y siente, se piensa y se siente, siendo él mismo un cliché entre otros en el mundo que lo rodea (281).

Como advertíamos, la noción de figura posee cierta filiación con lo que Deleuze sistematizará como imagen óptica-sonora pura en L'image-temps, especialmente con respecto al carácter emancipador de las directrices figurativas, sensorio-motores, pero también con un pensamiento que le dará a la imagen un estatuto no referencial, es decir, no subordinado directamente a algún tipo de discursividad que circunscriba la misma operación de las imágenes. En relación con ello se debe precisar que la figura

que para Deleuze resultan absolutamente claves, citamos: "El término 'figurativo' indica la posibilidad de derivar el objeto pictórico a partir de su modelo "real" por una traslación continua. El trazo en el cuadro figurativo es un trazo no-arbitrario. La figuratividad es pues una propiedad relativa a la relación del objeto plástico con aquello que representa. Desaparece si el cuadro ya no tiene por función la de representar, si es él mismo el objeto" (Lyotard 292).

6 En su traducción al castellano, Irene Agoff -hasta ahora la única que existe de los dos volúmenes sobre cine- se inclina por traducir "clichés" por "tópicos". Creemos que esta traducción, a partir de lo que Deleuze señala, es injusta con su propio pensamiento, debido a que es una noción mucho más preponderante en su obra anterior, Francis Bacon. Lógica de la sensación. Nosotros conservamos el término cliché, tanto en las referencias directas o en los parafraseos. Esta decisión pasa exclusivamente por un criterio de coherencia con respecto a lo que estamos tratando de plantear. 
no se opone de manera simple a la figuración: la distancia que tomará Deleuze -como también Bacon- del formalismo y del expresionismo abstracto es clave para entender este asunto (Buydens 154-58). Sin duda, lo abstracto en pintura acabó con la figuración; pero no para producir una figura en pintura, sino para acrecentar una posibilidad del cliché en pintura. La figura es un mínimo de figuración (Deleuze dirá: en Bacon se ve al sacerdote, se ve algo), ${ }^{7}$ quizás en tanto es "forma sensible" de la sensación, se asemejará al objeto, pero no figurativamente y, tratará de llegar a la semejanza "bajo medios accidentales y no semejantes” (Logique du sens 92). Por esta misma razón, la imagen pictórica constituye una imagen más profunda, de una semejanza más profunda que no remite al objeto del cual es molde. Con la imagen cinematográfica funciona el mismo procedimiento: "arrancar a los clichés una verdadera imagen" (L’image-temps 32).

Todo este asunto, en definitiva, tiene estricta relación con aquello que planteábamos en un principio: con la configuración del "empirismo trascendental" en tanto estética, en el sentido de que los clichés fueron definidos por Bacon como posibilidades de ver, y para Deleuze, sin lugar a dudas, son una forma de lo empírico, una condición de posibilidad de lo empírico. Zourabichvili ha puntualizado que efectivamente "el cliché es una forma de lo posible" (Deleuze y lo posible 147), estrictamente en la medida en que se comprende que todo está dado, que nada está para realmente efectuarse, para ser real. Deleuze concibe al cliché bajo la misma operación que trata de calcar lo trascendental sobre lo empírico, es decir, hacerlo una especie de imagen representativa del acontecimiento o de lo irruptivo. Nada nuevo germinará, no habiendo ni creación ni pensamiento. De allí que la "experiencia real implica al contrario la afirmación de una relación radical con eso que todavía no se piensa” (147). Es en este sentido también que Deleuze dirá, a partir de Bacon, que las fotografías son una suerte de medio o recurso (moyens) para ver (Logique du sens 86), o bien, en otras palabras, una posibilidad para ver. Si el problema de Deleuze con la fotografía está tematizado de mayor manera en el libro sobre Bacon, en los volúmenes sobre cine también se encuentra perfilado del siguiente modo: la fotografía se halla en una dimensión estrictamente figurativa, es decir, son justamente los datos figurativos, las imágenes que pueblan y de las cuales hay que deshacerse. Con ello aparece otra arista que anuda la estética de Deleuze cuando desarrolla la filiación entre imagen pictórica e imagen cinematográfica, que correspondería a una revisión de la noción simondiana de modulación.

\section{Modulación (la analogía estética)}

La noción de modulación que Deleuze invoca en sus estudios sobre pintura, a partir de una lectura de Gilbert Simondon (La individuación 57-62), la refiere para pensar

7 Francis Bacon - Study after Velazquez's potrait of Pope Innocent X, 1953. 
el estatuto de una imagen analógica no anclada en la similitud. Sin embargo, el concepto que acuña Simondon tiene relación en primer lugar con disolver el primado del esquema hilemórfico, impotente para la tarea de pensar realmente la individuación. Una de las pocas comentadoras que ha relacionado rigurosamente la influencia del pensamiento de Simondon en Deleuze es Anne Sauvagnargues. Ella ha señalado al respecto que el concepto de modulación brinda un acceso importante a la hora de disolver la antigua dualidad entre la materia y la forma, citamos:

La confrontación abstracta de la materia y de la forma, en la concepción hilemórfica del moldeado (moulage), no puede explicar la adaptación de forma al nivel de las fuerzas. La modulación (modulation) del ladrillo pone en juego la operación común entre la materia formada y la forma material, su interacción concreta, tienen un mismo nivel de existencia (Lempirisme transcendantal 250).

Ahora bien, nos interesa rastrear el concepto de modulación en la pregunta que acomete Deleuze en torno a la pintura, para encontrar cómo el lenguaje pictórico tiene su propia especificidad al ser diferenciado de la fotografía. La clave de esta respuesta viene precedida de un establecimiento o distinción mínima con respecto a la imagen analógica, pudiendo ser pensada como reproducción pero también como producción. Para Deleuze, la distancia entre ambos tipos de analogía pasa por una relación distinta con la semejanza, ya que es reproductora cuando las relaciones de los elementos de una cosa pasan directamente a otra, volviéndose desde ahí la imagen (representación) de la primera. Movimiento cercano a la operación de la fotografía, que captura las relaciones de luz (Pintura. El concepto de diagrama 133) desde un principio de reproducción de la semejanza: es decir, in-forma, da una forma a una superficie determinada, como por ejemplo el molde sobre la arcilla (Simondon 50). Deleuze puntualizará que existe un tipo de analogía común que grafica dentro de la operación del molde para pensar una especie de analogía superior, que llamará estética y que operaría a partir de la modulación.

Es por esto que, para Deleuze, la fotografía no superaría una dimensión de la analogía definida meramente a partir del transporte de relaciones de similitud, es decir, la analogía común. En otras palabras, la fotografía solo reproduce la semejanza, y Simondon diría que moldea más que modular. Por su parte, la singularidad de la pintura se establece en cuanto otorga una semejanza mucho más profunda, produciendo la semejanza -aquello que Bacon llamó la figura-: la pintura produce la semejanza (ressemblance) por medios no semejantes, produce semejanza por medios completamente distintos que el transporte de similitudes. Con la pintura se está ante una figura con la cual no se tiene necesidad de ver el modelo para estar convencidos de la semejanza que guarda la obra (Logique du sens 108-9). A este tipo de analogía Deleuze la bautiza como propiamente estética, concediéndole a la pintura tal lugar en detrimento de la fotografía, la cual siempre estará remitida a una esfera estrictamente figurativa: 


\begin{abstract}
De modo que no veo cómo la fotografía podría superar el aspecto que podemos llamar figurativo. Lo que llamo figurativo no lo es para nada en la medida en que se asemeja a algo, lo es en la medida en que la imagen es producida por un transporte de relación similar, por una similitud de relación, pudiendo ser esta similitud, en última instancia, relajada tanto como ustedes quieran. Diríamos que la fotografía vive y tiene su condición de posibilidad en la analogía común, en el transporte de similitud (Pintura 133, cursivas nuestras).
\end{abstract}

De esta manera, la lógica de la pintura es el orden de la modulación, terreno específico de la pintura, que significa básicamente moldear de manera continua y permanentemente variable. Bajo la misma fórmula, Deleuze enuncia a la imagen cinematográfica, que emparenta como lenguaje analógico con la pintura. Esto en el sentido que el corte móvil, que permitiría la realización de la imagen-movimiento -y no ser una imagen en movimiento-, tendría el cariz de una modulación. Así, Deleuze hace tomar distancia a la imagen cinematográfica de la fotografía:

La fotografía es una suerte de «moldeado» (moulage): el molde organiza las fuerzas internas de la cosa de tal manera que en un instante determinado alcanzan un estado de equilibrio (corte inmóvil). Mientras que la modulación (modulation) no se detiene por haberse alcanzado el equilibrio, y no cesa de modificar al molde, de constituir un molde variable, continuo, temporal (L'image-mouvement 39).

De este modo, el linaje tecnológico del cine no estará relacionado con la fotografía, más bien existiría una filiación más profunda con la pintura. La clave de esta cuestión es la dimensión analógica que se le concede a ambas, pues esta analogía es pura variación continua de su cualidad y no el molde finito e inmóvil de un transporte de similitud. Al asimilar la imagen desde la similitud supone el problema de eliminar de ella el movimiento, el carácter metamórfico y variable. Con este dato se establece que la especificidad de la imagen cinematográfica radica en su carácter moviente, que no reproduce simplemente una semejanza. La imagen-movimiento, en este sentido, no es analógica desde la similitud: no se asemeja a un objeto al que ella representa. Esto fue lo que demostró Bergson en Materia y memoria (35-94), remarcando el carácter de las imágenes. Estas no están depositadas en la conciencia, pues si los objetos son cosas con las cuales la conciencia debe entrar en relación, aquello solo es pensable en un universo de objetos inmóviles, y no en un universo de variación continua. ${ }^{8} \mathrm{La}$

8 La noción de "variación continua" es trabajada más rigurosamente en Postulados de la lingüística, donde es tematizada desde, justamente, un tratamiento en torno a la lengua (hacer de la lengua mayor una potencia de variación continua) (Mille Plateaux 132). Pero también es proyectada a un análisis de cierta potencia de la música, en el sentido de poner en juego una variación continua que no necesitaría dar forma a través de lo sonoro a una determinada materia, puesto que el "conjunto materia-forma es ahora sustituido por la interacción material-fuerzas. El sintetizador ha sustituido al antiguo 'juicio sintético a priori', como consecuencia, todas las funciones cambian. Al poner en variación continua todos las componentes, la música deviene un sistema sobrelineal, un rizoma en lugar de un árbol, y pasa al servicio de un continuum cósmico virtual, del que hasta los agujeros, los silencios y las rupturas, los 
imagen-movimiento es el objeto, es la cosa misma captada en el movimiento como función continua o, en otras palabras, la imagen-movimiento es la modulación del objeto mismo. Es así como Deleuze logra dotar de un espesor ontológico a las imágenes: frente a los objetos estas suponen una modulación, son la realidad física de las cosas, y no una duplicación de la misma o una copia. Si bien, como estamos exponiendo, la modulación opera por variación, también moldea y, transforma el molde en cada momento, variándolo, matizándolo, haciendo de la forma un flujo incesante. Por lo tanto, no podríamos aducir que aquello que se mueve sean, en definitiva, formas, porque al comprenderlo de esa manera se seguiría pensando en una dialéctica del movimiento, es decir, en que la forma se actualiza en la materia. La modulación funciona precisamente en una variación continua de la misma materia, porque la materia es aquello que no deja de variar, de moverse. El molde pertenece a una lógica de las formas, en cambio la modulación pertenece al movimiento infinito de la materia.

\section{Conclusión}

La filosofía de Deleuze es en sí misma una paradoja. Esto lo han constatado varios de sus comentadores, como por ejemplo Villani, quien ha sostenido que la gran paradoja existente en el trabajo deleuzeano comprende la existencia de una metafísica que se define a partir de un principio de inmanencia. Tradicionalmente, la metafísica siempre fue definida a partir de un principio de trascendencia, es decir, de aquello que se opone radicalmente a cualquier atisbo de inmanencia (Pli selon pli 39). Es en este sentido que la estética para Deleuze toma el lugar de una metafísica. El movimiento filosófico que el mismo Deleuze no pareciera explicitar, para nosotros posee una profunda relevancia en el desarrollo del que creemos su más importante libro, Différence et répétition. La distinción elemental que hará Deleuze allí es, en primer lugar, exponer en qué sentido esta estética -que sin duda es trascendental-se diferencia de Kant, en el sentido de que las sensaciones no están dadas, ya hechas. Kant las llevaba simplemente al terreno de lo a priori, estableciendo que lo trascendental guardaba relación, antes que todo, con un condicionamiento. La avanzada de Deleuze está en concebir que las condiciones sean genéticas, es decir, altera totalmente el universo de las sensaciones, al comprenderlas como germinales. En otras palabras, lo sensible es producido a partir de un proceso en el cual ciertas fuerzas provocan la génesis de la sensibilidad. De esta manera, el lugar de las condiciones lo ocuparán las fuerzas, aunque este lugar no sea simplemente el de lo condicional, en el sentido en que es condición posible de la experiencia. Por el contrario, las fuerzas son condiciones reales

cortes forman parte" (120-121). Creemos sostener que la modulación contiene una lógica de la variación continua, en el sentido de su infinito moldear pero también en cómo ya no daría ninguna forma a una determinada materia sino que más bien haría de la materia una continua variación. 
de la sensación, y esto supone concebirlas desde una perspectiva trascendental, es decir, no como un elemento meramente empírico: para que lo sensible germine debe producirse desde lo no-sensible, desde lo no-sentido. Esta hipótesis de trabajo es la que tratamos de desarrollar, al rastrearla en los trabajos de Deleuze donde la sensación aparece bajo una forma más sensible, particularmente en sus trabajos sobre pintura o cine que, como hemos visto, constituyen una puesta en juego más concreta de aquello que durante los años sesenta él cimentó como una metafísica donde lo esencial era más la búsqueda de un principio de la inmanencia que un principio trascendente.

\section{Referencias}

Bergson, Henri. Materia y memoria. Ensayo sobre la relación del cuerpo con el espíritu. Buenos Aires: Cactus, 2006. Impreso.

Buydens, Mireille. Sahara. Lesthetique de Gilles Deleuze. Paris: Vrin, 2005. Impreso. Deleuze, Gilles. Empirisme et subjetivité. Paris: PUF, 1953. Impreso.

---. Proust et les signes. Paris: PUF, 1964. Impreso.

---. Le bergsonisme. Paris: PUf, 1966. Impreso.

---. Présentation de Sacher Masoch. Le froid et le cruel. Paris: Les editions de minuit, 1967. Impreso.

---. Différence et répétition. Paris: PUf, 1968. Impreso.

---. Logique du sens. Paris: Les editions de minuit, 1969. Impreso.

---. Cinéma 1. L'image-mouvement. Paris: Les editions de minuit, 1983. Impreso.

---. Cinéma 2. L'image-temps. Paris: Editions du minuit, 1985. Impreso.

---. Francis Bacon. Logique de la sensation. Paris: Éditions du Seui, 2002. Impreso.

---. Pintura. El concepto de diagrama. Buenos Aires: Cactus, 2007. Impreso.

---. Cine 1. Bergson y las imágenes. Buenos Aires: Cactus, 2009. Impreso.

---. y Guattari, Félix. Kafka. Pour une littérature mineure. Paris: Les editions de minuit, 1975. Impreso.

---. Mill Plateaux. Capitalisme et schizophrénie. Paris: Les editions de minuit, 1980. Impreso.

Heidegger, Martin. ¿Qué significa pensar? Madrid: Trotta, 2005. Impreso.

Kant, Immanuel. Crítica de la razón pura. Madrid: Taurus, 1997. Impreso.

---. Crítica de la facultad de juzgar. Trad. Pablo Oyarzún. Caracas: Monte Ávila Editores, 2006. Impreso.

Lapoujade, David. Los movimientos aberrantes. Buenos Aires: Cactus, 2016. Impreso. Lyotard, Jean François. Discurso, figura. Trad. Isaac Dentrambasaguas y Roman Antropolsky. Buenos Aires: La Cebra, 2014. Impreso.

Montebello, Pierre. Deleuze, philosophie et cinéma. Paris: Vrin, 2008. Impreso.

Montenegro, Gonzalo. Empirismo trascendental. Génesis y desarrollo de la filosofía de Gilles Deleuze. Bógota: Bonaventuriana, 2013. Impreso. 
Pardo, José Luis. Las formas de la exterioridad. Valencia: Pre-textos, 1992. Impreso. ---. El cuerpo sin órganos. Presentación de Gilles Deleuze. Valencia: Pre-textos, 2011. Impreso.

Rancière, Jacques. “¿Existe una estética deleuzeana?”. Gilles Deleuze. Una vida filosófica. Ed. Eric Alliez. Medellín: Revista Euphorion, 2002. 205-211. Impreso.

---. El malestar de la estética. Trad. Miguel Petrecca, Lucía Vogelfang y Marcelo G. Burello. Buenos Aires: Capital Intelectual, 2011. Impreso.

Sasso, Robert y Villani, Arnaud. Le vocabulaire de Gilles Deleuze. Paris: Vrin, 2003. Sauvagnargues, Anne. Deleuze et l'art. Paris: PUF, 2006. Impreso.

---. L'empirisme transcendantal. Paris: PUf, 2009. Impreso.

Simondon, Gilbert. La individuación. A la luz de las nociones de forma e información. Buenos Aires: Cactus-La Cebra, 2009. Impreso.

Villani, Arnaud. "De l'esthétique à l'esthésique: Deleuze et la question de l'art". Gilles Deleuze. Héritage philosophique. Ed. Alain Beaulieu. Paris: Vrin, 2005. 97-121. Impreso.

---. "Pli selon pli. Gilles Deleuze et l'acte esthétique". Gilles Deleuze, la logique du sensible. Esthétique et clinique. Dir. d'Adnen Jdey. Rhône-Alpes: De l'indicidence éditeur, 2013. 39-58. Impreso.

Zourabichvili, François. "Deleuze y lo posible (del involuntarismo en política)”. Gilles Deleuze. Una vida filosófica. Ed. Eric Alliez. Medellín: Revista Euphorion, 2002. 137-150. Impreso.

---. Le vocabulaire de Deleuze. Paris: Ellipses, 2003. Impreso.

---. Deleuze, una filosofía del acontecimiento. Buenos Aires: Amorrortu, 2004. Impreso.

Recibido: 11 abril 2017 Aceptado: 23 agosto 2017 